\title{
Direito à educação escolar: o discurso da inclusão x a prática da exclusão
}

\section{Right to school learning: the inclusion discourse $x$ the exclusion practice}

\author{
Dília Maria Andrade Glória*
}

\begin{abstract}
RESUMO
Neste estudo, discute-se as dificuldades do reconhecimento dos direitos humanos após a Revolução Francesa de 1789 e, em especial, o direito à educação pública escolar. Na busca por conhecer as condições que favorecem a inclusão escolar, examina-se a situação do fracasso escolar no Brasil, bem como mudanças recentes implementadas por políticas públicas, em particular o princípio da nãoretenção escolar na Escola Fundamental. Conclui-se que ainda permanece uma grande distância entre o que é legalmente proclamado e o que é realmente efetivado em termos do direito à educação no Brasil.

Palavras-chave: direito à educação, fracasso escolar, inclusão escolar.
\end{abstract}

\begin{abstract}
In this study, I discuss the difficulties of acknowledging human rights after the French Revolution of 1789, and in special, the right to attend a public school education. In the search for knowing the conditions for school inclusion, I examine the situation of school failure in the Brazil, as well as, recent changes implemented by public policies, in particular, the School NonRetention Projects for Elementary Schooling. I came to the conclusion that still remains a great distance between what is legally proclaimed and what is really accomplished in terms of one's right to education in Brazil.

Key-words: the right to attend a school education, school failure, school inclusion.

* Mestre em Educação pela PUC-MG. Professora da Escola Fundamental do Centro Pedagógico da UFMG. dilia@ dedalus.lcc.ufmg.br
\end{abstract}


O problema do reconhecimento dos direitos humanos é mais do que nunca uma questão em pauta. Discute-se, proclama-se, luta-se pelo que se considera direito do ser humano. Dentre esses direitos, a educação escolar é considerada fundamental (MARSHALL, 1967; PRZEWORSKI, 1989; BOBBIO, 1992), todavia essa é uma constatação que pode ser considerada como historicamente recente, sobretudo, em termos legais (CURY, 2000). Além disso, mesmo proclamada como direito social, reconhecida legalmente em quase todos os países do mundo desde a Segunda Guerra Mundial, a educação escolar não é ainda uma certeza para todos, mesmo que mínima, haja vista que o compromisso do Estado tem geralmente se limitado ao Ensino Fundamental: oito a dez anos conforme o país, quando não somente os quatro primeiros anos de escolarização (HORTA, 1998).

Ao abordar esse tema, воввіо (1992) ressalta que, sobretudo com a Revolução Francesa e após a Segunda Guerra Mundial, passou-se, mediante uma evolução histórica - a grande virada da modernidade - não apenas ao reconhecimento dos direitos do indivíduo, mas a sua ampliação. A moral era vista, até essa época, apenas na ótica da sociedade e, portanto, restrita a deveres. $\mathrm{O}$ autor considera tal fato um sinal positivo do nosso tempo. Entretanto, mesmo otimista, argumenta que:

Finalmente, descendo do plano ideal ao plano real, uma coisa é falar dos direitos do homem, direitos sempre novos e cada vez mais extensos, e justificá-los com argumentos convincentes; outra coisa é garantir-lhes uma proteção efetiva. Sobre isso, é oportuna ainda a seguinte consideração: à medida que as pretensões aumentam, a satisfação delas torna-se cada vez mais difícil. Os direitos sociais, como se sabe, são mais difíceis de proteger do que os direitos de liberdade. (воввіо, 1992, p. 63).

De fato, a garantia dos direitos sociais (educação, saúde, moradia etc.) implica num alto custo financeiro, o qual o Estado democrático tem assumido muito mais no papel (refere-se aqui à Lei, expressão mais manifesta do direito) do que efetivamente na prática cotidiana.

Há, pois, uma lacuna entre a educação proclamada como um direito social e sua efetivação na prática. Um passo significativo na proteção ao direito social educacional é defini-lo, constitucionalmente, como direito pú- 
blico subjetivo, ou seja, "aquele pelo qual o titular de uma prerrogativa pode fazer cumprir um dever cuja efetivação apoia-se em um dispositivo legal que visa à satisfação de um bem indispensável à cidadania" (CURY, 2000, p. 575). Nesse sentido, a presença do Estado é indispensável a fim de desenvolver políticas públicas adequadas no campo social. Obviamente, isso não irá se concretizar sem a efetiva participação da sociedade civil para conquistar, manter e garantir seus direitos. Como afirma PRZEWORSKI (1989), ao discutir a construção histórica da social-democracia na Europa: "Se pretendem fazer uso das oportunidades oferecidas pela democracia, os trabalhadores devem organizar-se como participantes". Percebese, pois, uma vinculação incontestável entre educação e cidadania. Todavia, como lembra Gentili (2000), deve-se discutir o caráter dessa vinculação. Portanto, cabe esclarecer em que termos ela se dá, como foi historicamente construída e como ela hoje é pensada.

É a partir da Revolução Francesa, com a ascensão da classe burguesa ao poder, que pela primeira vez se pensa a educação como um direito de todos os cidadãos (HORTA, 1998). Analisando-se, porém, essa relação, que se estabelece entre educação, direito e cidadania, conclui-se que tanto a cidadania como o direito têm aqui um caráter restrito e restritivo. Em outras palavras, não são muitos os indivíduos considerados cidadãos.

воввіо (1992, p. 62) chama a atenção para a tendência atual de se determinar, em se tratando de direitos, a que cidadão se faz referência: “que homem, que cidadão?". Há certas especificidades nessa questão de direitos que devem ser contempladas face às diferenças existentes, como é o caso da Declaração dos Direitos da Criança, proclamada em 1959. Essas diferenças, sejam naturais ou culturais - diferenças de gênero, de raça, de capacidade física e mental, de idade, de religião, de classe social etc. -, acabam, porém, por justificar desigualdades sociais, valendo-se de um juízo comparativo de superioridade de um grupo em relação a outro e, muitas vezes, "fundamenta por posições jurídicas nítidas: tal grupo tem direitos próprios, que são conhecidos, na linguagem tradicional do Direito, como privilégios; outro não tem direitos, é um subgrupo, não pode se igualar aos demais" (COMPARATO, 1998, p. 47). Assim, por exemplo, numa sociedade de base escravocrata e machista como a brasileira, negros e mulheres sofrem ainda discriminação e têm que batalhar continuamente pela garantia dos direitos já conquistados. Bastaria lembrar que a mulher só foi adquirir direito ao voto muito depois que o homem. Como ressalta Gentilli (2000, p. 149): 
Se é evidente que o reconhecimento formal dos direitos é uma condição central para a construção de uma comunidade de cidadãos e cidadãs, também o é o fato de que uma cidadania reduzida a critérios jurídicos é quase sempre, uma cidadania vazia.

Dessa forma, a verdadeira cidadania tem se constituído, pois, em termos de lutas históricas, caracterizando-se como um direito conquistado e não meramente outorgado por aqueles que detêm o poder econômico e político-social.

Por outro lado, o direito social como elemento integrante da cidadania foi o último a se formalizar. Referindo-se à Inglaterra, MARSHALL (1967, p. 75) diz que:

...os direitos civis surgiram em primeiro lugar e se estabeleceram de modo um tanto semelhante à forma moderna que assumiram antes da entrada em vigor da primeira Lei de Reforma, em 1832. Os direitos políticos se seguiram aos civis e a ampliação dêles (sic) foi uma das principais características do século XIX, embora o princípio da cidadania da política universal não tenha sido reconhecido senão em 1918. Os direitos sociais, por outro lado, quase que desapareceram no século XVIII e princípio do século XIX. O ressurgimento dêstes (sic) começou com o desenvolvimento da educação primária pública, mas não foi senão no século XX que êles (sic) atingiram um plano de igualdade com os outros elementos da cidadania.

Portanto, no final do século XIX, inicia-se um novo período, no qual:

Os componentes de uma vida civilizada e culta, originariamente o monopólio de poucos, foram, aos poucos, postos ao alcance de muitos. A diminuição da desigualdade fortaleceu a luta por sua abolição, pelo menos com relação aos elementos essenciais do bem-estar social (MARSHALL, 1967, p. 88). 
Esses bens e serviços sociais essenciais, como assistência médica, moradia, educação ou um salário mínimo capaz de arcar com tais despesas, são explicados por marshall (1967, p. 96) como sendo o mínimo social a ser garantido pelo Estado:

Um mínimo de direitos legalmente reconhecidos pode ser concedido, mas o que interessa ao cidadão é a superestrutura das expectativas legítimas. (...) E, assim, verificamos que a legislação, ao invés de ser o fator decisivo que faça com que a política entre em efeito imediato, adquire, cada vez mais, o caráter de uma declaração política que, segundo se espera, entrará em vigor algum dia.

Da mesma forma que na Europa, assim parece ter ocorrido também no Brasil, com os direitos sociais sendo tardiamente assinalados nas Constituições Federais (CURY; HORTA; FÁVERO, 1996). Tanto é assim que somente na Constituição de 1988 se institui o Ensino Fundamental obrigatório como direito público subjetivo, ou seja, o indivíduo poderá acionar mecanismos jurídicos que lhe garantam esse direito quando o Estado não cumprir com seu dever de efetivá-lo (PALMA FILHO, 1998).

Para CURY (2000, p. 581):

O importante é que a educação escolar não deixe de ser reconhecida como um serviço público, daí a importância de toda a educação básica se tornar um direito público subjetivo. Se muito deve ser feito no campo da distribuição da renda de modo a termos um país mais igual, só uma maior igualdade permite a valorização afirmativa das diferenças.

Ainda comentando sobre o direito à educação no Brasil, CURY (2000, p. 569) afirma que:

Nossa cidadania educacional está longe de ser um exemplo. Convivemos com milhões de crianças fora da escola ou presentes na escola, mas fora da 
idade apropriada. Avançamos muito nesse campo, mas enquanto houver uma criança sem escola ou fora da idade adequada, o direito de todos e o dever do Estado não terão se consubstanciado. Temos milhões de jovens e adultos que não tiveram a oportunidade de entrar na escola ou dela tiveram que se evadir mais cedo, por condições de sobrevivência ou por repetência. A educação infantil e o ensino médio ainda são privilégio.

A análise do autor é a de que "a importância da educação para o processo de construção da democracia no país sempre foi muito enfatizada, mas não necessariamente efetivada" (CURY, 2000, p. 583). Fica claro que há uma discrepância significativa entre o "discurso da inclusão", que proclama o direito de todo cidadão à educação escolar, e a realidade prática, que continua a excluir muitos indivíduos do exercício da cidadania.

De fato, no Brasil, desde a década de 30, com a democratização das escolas públicas, observam-se altos índices de situações de fracasso escolar com a configuração de uma realidade escolar capaz de reprovar e excluir milhares de crianças de seu sistema de ensino. Na década de 50 do século XX, Anísio Teixeira já discutia as elevadas taxas de reprovação, repetência e evasão escolar, afirmando o direito de todos a uma educação escolar pública e a importância de medidas governamentais para democratizar as oportunidades educacionais no Brasil (TEIXEIRA, 1994). Mas é a partir de 1980 que há a introdução de mudanças na política educacional por parte de grupos mais progressistas em alguns Estados, que, além de democratizarem o acesso à escola, visam ainda à qualidade do ensino: materiais didáticos diversificados, autonomia administrativa, melhoria das condições físicas das escolas, valorização do professor (salário, carreira, qualificação...), gestão pedagógica democrática etc. (sILva et al., 1993). No entanto, embora importantes, essas mudanças não têm surtido o efeito desejado, acredita-se, por não atingirem o cerne da questão, por não alterarem a estrutura do sistema.

No final dos anos 80 e início da década de 90, surgem propostas consideradas mais inovadoras e mesmo radicais, em que se busca uma reorganização dos tempos e espaços escolares. Dessa forma, na busca da inclusão escolar, são definidas estratégias político-pedagógicas, como o regime de ciclos, não-retenção escolar, classes de aceleração... Tais mudanças são, inclusive, respaldadas e indicadas pela nova Lei de Diretrizes e Bases da Educação Nacional (LDB), de dezembro de 1996, que, aliás, avançou no que se refere à 
descentralização e flexibilidade, vindo a favorecer as novas políticas pedagógicas (PRADO, 2000). ${ }^{1}$ A LDB "reafirma, através de mecanismos de reclassificação, de aceleração de estudos e de avanços progressivos, o propósito de eliminar, gradualmente, as distorções idade/série, geradas no âmago da cultura da reprovação" (CURY; HORTA; BRITO, 1997, p. 255).

Nesse sentido, são implementadas propostas político-pedagógicas em diversas escolas das redes municipais, estaduais e no Distrito Federal: "Escola Plural, em Belo Horizonte; Escola sem Fronteiras, em Blumenau; Escola Cidadã, em Porto Alegre; Escola Desafio, em Ipatinga; Escola Candanga, em Brasília, e outras tantas que, em sua diversidade, apontam perspectivas comuns" (ARROYO, 2000, p. 33). Essas propostas, alicerçadas na gestão democrática da escola, redimensionam o espaço, o tempo e a organização do trabalho escolar, objetivando instaurar uma lógica da inclusão que propicie a todos os alunos uma aprendizagem efetiva com vistas à cidadania. Para PRADO (2000, p. 53), trata-se de uma mudança de mentalidade que "passa necessariamente pela busca de alternativas para a substituição da 'cultura da repetência' por uma prática pedagógica voltada para o sucesso do aluno" e que requer um "longo e complexo processo" a fim de resultar em uma mudança comportamental. Segundo ARROYO (2000, p. 34), "pretendemos enfrentar a seletividade inerente à lógica estruturante dos currículos, das séries, das grades, da organização do trabalho, dos tempos e espaços. Pretendemos chegar à matriz do fracasso/sucesso". A preocupação explícita é a de eliminar os mecanismos e procedimentos escolares que tradicionalmente produzem a exclusão das camadas mais populares. Dentre esses mecanismos, são ressaltados a eliminação da reprovação e da repetência por meio dos ciclos:

É necessário reduzir as rupturas nos processos de socialização provocadas pela reprovação, reconhecendo a força socializadora e formadora do convívio entre alunos e alunas da mesma idade ou ciclo de formação. Ao reconhecer que a educação é um direito fundamental, a escola precisa garantir que o processo de formação se dê de forma ininterrupta, junto aos pares de idade (BAPTISTA, 1998, p. 4). ${ }^{2}$

1 Na verdade, quando a LDB admitiu a possibilidade de organização por ciclos em contraposição ao regime seriado, de caráter conteudista e seletivo, algumas propostas já haviam sido implantadas, como é o caso da Escola Plural, em Belo Horizonte, que iniciou-se oficialmente em 1994.

2 Disponível em: 〈http://www.belohorizonte.mg.gov.br/smed/escoplur/escoplu00.htm> 
Mas, aliado a isso, esses programas revelam que "eliminar a possibilidade de reprovação escolar é um caminho necessário à garantia da aprendizagem para todos, embora não suficiente", e são, pois, desenvolvidos "mecanismos institucionais de inclusão" (PORTO ALEGRe, [199-]). ${ }^{3}$ Dentre esses, tem sobressaído a formação de turmas especiais compostas por alunos que apresentem uma defasagem entre o nível de sua escolaridade e sua faixa etária. Tais turmas têm recebido denominações diferentes, como "turmas de progressão" (Escola Cidadã) ou "turmas de aceleração" (Escola Plural), mas sempre com o propósito de inclusão e almejando que os alunos delas integrantes possam desenvolver sua auto-estima, sentindo-se capazes e estimulados a aprender. Nesse caso, trata-se de uma estratégia traçada dentro de uma nova concepção pedagógica.

Como se pode perceber, as propostas e programas político-pedagógicos que vêm sendo desenvolvidos a partir de 1990 têm em comum vários aspectos, inclusive a eliminação da reprovação escolar. E é justamente esse um dos pontos mais polêmicos, se não o maior, e percebido por muitos como uma das grandes dificuldades na busca do sucesso escolar.

Embora não haja, nas mencionadas propostas político-pedagógicas, a concepção ingênua de que ao se eliminar a reprovação, descarte-se o fracasso escolar e que a aprovação irá equivaler ao sucesso/qualidade (ARROYO, 2000), tem sido esse o foco da discussão. Os professores, pais e mesmo os alunos têm questionado o fato de se estar passando de ano sem os conhecimentos e competências exigidos pela sociedade contemporânea (leiase: vestibular, concursos públicos, mercado de trabalho etc.), uma vez que a escola "tende a se tornar meio para outro fim: o diploma e, com ele, a esperança de um emprego melhor, ou uma certa estabilidade ocupacional" (DAYRELL, 1996, p. 157). Dessa forma, aqueles que anteriormente eram excluídos por não terem acesso ou possibilidades de permanência na escola, hoje seriam excluídos pelo não-domínio das competências escolares.

ARROYO (1999, p. 1), em artigo publicado no jornal Estado de Minas, preocupa-se em esclarecer que: "Nunca foi intenção da Escola Plural nem das outras propostas facilitar o fluxo escolar, inventar um método para não reprovar, passar todos, aprendam ou não". Entretanto, a sociedade tem expressado preocupação com a eficácia das intervenções realizadas a fim de garantir uma aprendizagem real e efetiva. Artigos recentes publicados em jornais e revistas de grande divulgação no país têm discutido essa ques-

3 Disponível em: 〈http://www.portoalegre.rs.gov.br/smed/escola.htm> 
tão. O jornal Estado de Minas, de 11 de outubro de 1999, relata que, em São José do Rio Preto, no Estado de São Paulo, alunos do quarto ano do Ensino Fundamental "sabem apenas 'desenhar o nome' mas não conseguem identificar as letras". Esse fato levou o secretário municipal de Educação a criticar severamente o sistema de "progressão continuada" (o aluno cumpre um ciclo de quatro anos sem reprovação) implantado pelo governo estadual paulista, "alegando que a promoção automática está criando uma geração de 'diplomados analfabetos"”. Segundo o artigo, o mesmo ocorre em Araçatuba, também uma cidade de São Paulo, só que "os pais se rebelaram e ajuizaram ação contra o governo, exigindo que os filhos retornem às séries anteriores". E conclui:

A dúvida que fica: se no Estado mais rico acontecem tais distorções, imagine-se o que está acontecendo pelo País afora, especialmente nas escolas rurais, nas quais o professor é obrigado a ministrar quatro séries numa mesma sala para grupos diferenciados. Fazer propaganda não vale a pena quando o produto é ruim. Eé o que está acontecendo com a educação no País (Estado de Minas, 11 out. 1999).

Em março de 2000, a revista Veja deixa transparecer a idéia de que a educação está um "pouco melhor", pois embora o tempo de permanência na escola esteja maior, "o desafio agora é o aperfeiçoamento do ensino" (schivartche, 2000, p. 55). De acordo com o autor, o relatório da Organização das Nações Unidas para a Educação, Ciência e Cultura (Unesco) e da Organização das Nações Unidas para Cooperação e Desenvolvimento Econômico (OCDE) sobre condições de educação em 45 países, divulgado naquele mesmo período, aponta que "o Brasil tem a maior expectativa de repetência das crianças ao entrar no Ensino Fundamental (2,23 anos) entre os dezesseis países subdesenvolvidos estudados". Esse mesmo autor, numa posição contrária ao artigo anteriormente citado, sugere que se siga o exemplo do Estado de São Paulo, que implantou classes de aceleração e sistemas de ensino por ciclos, reduzindo assim as reprovações.

PENIN (2000, p. 3), no artigo "Repetência escolar: há ganhos?", na Folha de São Paulo, defende a progressão continuada e a superação da prática da repetência, alegando que ninguém, nem as crianças nem os pais, 
tampouco o país, ganha com "uma escola punitiva e seletiva, que serviu apenas às elites".

Em maio de 2000, a revista Isto É publicou uma reportagem intitulada "Ensino Reprovado". No texto, o autor parte de uma frase escrita por um aluno de 11 anos de uma escola municipal de São Paulo, frase de sentido incompreensível, para dizer que, em reprovação, "a escola, hoje, está formando, com diploma e carteirinha, subcidadãos despreparados para o futuro. Crianças, afinal, estão saindo da escola sem saber ler nem escrever" (NASCIMENTO, 2000, p. 54).

Nos textos "Educação na lógica do mercado" (PAIVA, 2000) e "Repetência no $1 .^{\circ}$ ano continua em 40\%" (GÓIs, 2000), publicados respectivamente no Estado de Minas e na Folha de São Paulo, constata-se que a evasão e a repetência no Brasil seguem elevadas, mesmo considerando-se a adoção da medida da não-retenção em muitos estados e municípios. Por outro lado, reportagens publicadas no jornal Estado de Minas sobre a Escola Plural apresentam a idéia de que se "bomba não educa ninguém", a mera permanência na escola não garante a aprendizagem e tem propiciado a exclusão educacional dos mais pobres. Assim, mesmo sem reprovação, muitos alunos do ensino básico, sobretudo aqueles oriundos de classes desfavorecidas socioeconomicamente, continuam apresentando um mau desempenho na escola (ARCE, 2000).

Configura-se, pois, uma discussão no âmbito nacional, não apenas nos meios educacionais e acadêmicos, mas também na mídia, sobre a estratégia da não-retenção escolar e suas implicações sociopedagógicas. Trata-se, sem dúvida, de uma medida muito questionada, sobretudo pelos professores e pais de alunos, que acreditam que os educandos estão sendo aprovados sem aprender o que deveriam, ou seja, a escola continua não cumprindo o seu papel e a exclusão permanece na medida em que o aluno está concluindo o Ensino Fundamental sem ter adquirido, muitas vezes, os conhecimentos básicos necessários para prosseguir em seu percurso escolar ou mesmo para obter uma colocação no mercado de trabalho e, com isso, será obviamente excluído em algum momento de sua trajetória escolar ou social. Assim, não obstante o discurso da inclusão, a prática da exclusão escolar e social parece persistir, embora evidenciada de forma clara mais tardiamente, quando da saída dos alunos do Ensino Fundamental e da constatação das desigualdades existentes em termos dos conhecimentos adquiridos no processo de escolarização, sobretudo dos alunos de classe popular. Talvez por isso, tem aparecido um discurso favorável à volta da 
reprovação e/ou do regime de seriação nas escolas. Contudo, quando se avalia o sistema de ensino seriado, percebe-se como ele é caracterizado por estruturas seletivas e excludentes, pautadas por uma lógica transmissiva e acumulativa de conteúdos. A escolarização do aluno faz-se num sistema seqüencial, num tempo determinado de um ano escolar que, por sua vez, fraciona-se em etapas avaliativas que estabelecem a assimilação de um mínimo de $60 \%$ dos conteúdos para a aprovação do aluno para a série seguinte. Caso contrário, o aluno repetiria o mesmo ano escolar. Trata-se de uma lógica perversa, pois, como considera DALBEN (1998, p. 60):

...prejudica duplamente os alunos que fracassam: primeiro porque são obrigados a repetir, no ano seguinte, conteúdos e atividades desenvolvidos no ano anterior, mesmo aqueles conhecimentos que dominaram; e em segundo porque se desligam de seu grupo de iguais, provocando interrupção nos processos de socialização.

Dessa forma, fechada em seus rituais de transmissão, promoção e retenção, a escola seriada e que reprova não se possibilita ser um espaço/ tempo de formação social e vivência cultural para os educandos, tal como proposto na ótica do sistema de ciclos de formação. Ademais, ignora as diferenças socioculturais dos diversos segmentos da população e inviabiliza o direito à educação das camadas populares. Há, pois, um avanço considerável em termos educacionais e sociais com a adoção do sistema de ciclos de formação.

No tocante à crítica estabelecida pelo senso comum quanto à prática da não-retenção escolar, é possível perceber que alguns alunos que evadiam da escola, muito em função da repetência, hoje nela permanecem, porque não há mais reprovação escolar. E mais: há relatos sobre alunos que, tendo desistido de estudar há algum tempo, têm retornado à escola, face às mudanças implementadas. Por outro lado, se hoje existem tantos alunos com sérias dificuldades face ao processo de ensino-aprendizagem ao final do Ensino Fundamental, em que se adotou o sistema de ciclos, isso parece dever-se, principalmente, ao fato de tratar-se de alunos que anteriormente eram excluídos muito cedo da escola. Assim, é um equívoco dizer que os problemas de aprendizagem hoje existentes em proporção muito mais elevada na escola são decorrentes do fato de não mais haver retenção escolar (GLÓRIA, 2002). 
Sem dúvida, não deve bastar que os alunos concluam o Ensino Fundamental, conforme previsto na Constituição Brasileira de 1988, como um direito. É preciso ir além do básico, estendendo-se a discussão do sucesso à qualidade da escolaridade: "Passa-se assim de um conceito bancário quantos dentro e quantos fora - para um conceito qualitativo sobre as aquisições, de quem está dentro e de quem está fora, para alcançar uma vida digna como brasileiro" (SPOZATI, 2000, p. 25). Mas a não concretização dos propósitos includentes e democráticos pela revisão e reformulação do papel social e das formas de organização pedagógica das escolas com a adoção do sistema de ciclos de formação não é razão para se pleitear a volta da reprovação e/ou do regime de seriação nas escolas. Afinal, a permanência dos alunos na escola está garantida. Agora, é preciso avançar e se pensar em estratégias que possibilitem a permanência dos alunos na escola com qualidade, de modo que as competências e os conhecimentos socialmente valorizados sejam de fato apreendidos.

Outro aspecto da questão diz respeito ao processo de incorporação das mudanças implementadas. Ao discutir o reconhecimento dos direitos construídos e implementados historicamente, MARShaLl (1967, p. 67) afirma que "O costume se constitui num dos grandes obstáculos à mudança”. De fato, deve-se ter claro que uma cultura não se altera radicalmente apenas em função de condições objetivas, embora sejam essenciais a qualquer mudança. Idéias, crenças, pensamentos e valores também devem ser revistos, reavaliados, reformulados. $\mathrm{Mu}$ danças que afetam tão profundamente o universo escolar requerem, sem dúvida, um tempo para análise, compreensão, ponderação, avaliação e mesmo convencimento da pertinência ou não da proposta implementada por todos os sujeitos envolvidos. E, assim, será possível esclarecer e alterar aspectos que possam contribuir para a revisão e o avanço da realidade educacional brasileira atual, uma vez que a prática da exclusão no que tange à educação escolar continua a confrontar o discurso e as medidas de inclusão que têm imperado nos meios políticos, educacionais e acadêmicos.

\section{REFERÊNCIAS}

ARCE, T. Bomba não educa ninguém. Estado de Minas, Belo Horizonte, 6 jun. 2000. Caderno Gerais/Educação, p. 26. 
. Pobreza é excluída da educação. Estado de Minas, Belo Horizonte, 23 nov. 2000. Caderno Gerais/Educação, p. 27.

ARROYO, M. G. A escola humanizada. Estado de Minas, Belo Horizonte, 12 jun. 1999. Suplemento Pensar, p. 1.

. Fracasso/sucesso: um pesadelo que perturba nossos sonhos. Em Aberto, Brasília, v. 17, n. 71, p. 33-40, jan. 2000.

BAPTISTA, M. C. Escola plural: direito a ter direitos. Disponível em: <http:// www.belohorizonte.mg.gov.br/smed/escoplur/escoplu00.htm> Acesso em: abr. 1998.

BELO HORIZONTE. Escola plural: proposta político-pedagógica da Rede Municipal de Educação. Belo Horizonte: Secretaria Municipal de Educação, out. 1994.

BOBBIO, N. A era dos direitos. Rio de Janeiro: Campus, 1992. A era dos direitos, p. 49-65.

COMPARATO, F. K. O princípio da igualdade e a escola. Cadernos de Pesquisa, São Paulo, n. 104, p. 47-57, jul. 1998.

CURY, C. R. J. A educação como desafio na ordem jurídica. In: LOPES, E. T.; FARIA FILHO, L. M.; VEIGA, C. G. (Org.). 500 anos de educação no Brasil. Belo Horizonte: Autêntica, 2000. p. 567-584.

CURY, C. R. J.; HORTA, J. S. B.; BRITO, V. L. A. de. Medo à liberdade e compromisso democrático: LDB e Plano Nacional de Educação. São Paulo: Editora do Brasil, 1997.

CURY, C. R. J.; HORTA, J. S. B.; FÁVERO, O. A relação educação-sociedade-estado pela mediação jurídico-constitucional. In: FÁVERO, O. (Org.). A educação nas constituintes brasileiras: 1823-1988. Campinas: Autores Associados, 1996. p. 5-30.

DALBEN, A. I. L. de F. A avaliação escolar: um processo de reflexão da prática docente e da formação do professor no trabalho. Belo Horizonte, 1998. 267 p. Tese (Doutorado em Educação) - Faculdade de Educação da UFMG. Capítulo 5: O processo de avaliação na sala de aula. p. 175-223.

DAYRELL, J. A escola como espaço sociocultural. In: . (Org.). Múltiplos olhares sobre educação e cultura. Belo Horizonte: UFMG, 1996. p. 136-161.

ESCOLA de analfabetos. Estado de Minas, Belo Horizonte, 11 out. 1999. Caderno Opinião, Editorial, p. 6.

GENTILI, P. Qual educação para qual cidadania? Reflexões sobre a formação do sujeito democrático. In: AZEVEDO, J. C. de; GENTILI, P.; KRUG, A.; SIMON, C. (Org.). Utopia e democracia na Educação Cidadã. Porto Alegre: Editora da UFGRS/Secretaria Municipal de Educação, 2000. p. 143-156.

GLÓRIA, D. M. A. A escola dos que passam sem saber: a prática da não-retenção escolar na narrativa de professores, alunos e familiares. Belo Horizonte, 2002. 237 p. Dissertação (Mestrado em Educação) - Departamento de Educação da PUC-MG. 
GLÓRIA, D. M. A. Direito à educação escolar: o discurso da inclusão...

GOIS, A. Repetência no 1. ${ }^{\circ}$ ano continua em 40. Folha de São Paulo, São Paulo, 8 set. 2000. Caderno Cotidiano, p. 1.

HORTA, J. S. B. Direito à educação e obrigatoriedade escolar. Cadernos de Pesquisa, São Paulo, n. 104, p. 5-34, jul. 1998.

MARSHALL, T. H. Cidadania, classe social e status. Rio de Janeiro: Zahar, 1967. Capítulo III: Cidadania e classe social, p. 57-113.

NASCIMENTO, G. Ensino reprovado. Isto É, São Paulo, n. 1597, p. 54-56, 10 maio de 2000.

PAIVA, D. Educação na lógica do mercado. Estado de Minas, Belo Horizonte, 16 jul. 2000. Caderno Opinião, p. 11.

PALMA FILHO, J. C. Cidadania e educação. Cadernos de Pesquisa, São Paulo, n. 104, p. 101-121, jul. 1998.

PENIN, S. T. de S. Repetência escolar: há ganhos? Folha de São Paulo, São Paulo, 6 abr. 2000. Caderno Brasil, p. 3.

PORTO ALEGRE. Secretaria Municipal de Educação. Escola cidadã. Disponível em: <http://www.portoalegre.rs.gov.br/smed/escola.htm> Acesso em: [199-].

PRADO, I. G. de A. LDB e políticas de correção de fluxo escolar. Em Aberto, Brasília, v. 17, n. 71, p. 49-56, jan. 2000.

PRZEWORSKI, A. Capitalismo e social-democracia. São Paulo: Cia. das Letras, 1989. Cap. 1: A social-democracia como um fenômeno histórico, p. 19- 65.

SCHIVARTCHE, F. Pouco melhor: aumentam os anos de estudo, mas qualidade ainda é desafio. Veja, São Paulo, n. 33, p. 55, 8 mar. 2000.

SILVA, R. N. da et al. O descompromisso das políticas públicas com a qualidade do ensino. Cadernos de Pesquisa, São Paulo, n. 84, p. 5-16, fev. 1993.

SPOSATI, A. Exclusão social e fracasso escolar. Em Aberto, Brasília, v. 17, n. 71, p. 2132, jan. 2000.

TEIXEIRA, A. Educação não é privilégio. 5 ed. Rio de Janeiro: Ed. UFRJ, 1994.

Texto recebido em 6 mar. 2002

Texto aprovado em 11 jun. 2002 